\title{
Ethical Navigation on Social Media
}

\begin{abstract}
This chapter provides conceptual tools for systematic decisionmaking for agents who are facing ethical dilemmas on social media. The Navigation Wheel offers a framework for analyzing concrete ethical dilemmas. The chapter illustrates how it can be used by analyzing a speech dilemma encountered by a professional handling an organization's Facebook page. A decision-maker can take each available option through the six questions in the Wheel before moving on to make a decisionLaw: Is it legal? Identity: Is it in accordance with our values? Morality: Is it right? Reputation: Does it affect our goodwill? Economy: Is it in accordance with our business objectives? Ethics: Can it be justified? Under the ethics heading, the decision-maker can apply the principle of equality and the principle of publicity to identify the ethically optional alternative. The same set of questions can also serve as a framework for ethical debriefing.
\end{abstract}

Keywords Ethical analysis $\bullet$ Decision-making $\bullet$ Social media $\bullet$ Ethical debriefing $\bullet$ Ethical dilemma 
The purpose of this chapter is to propose a set of conceptual tools to analyze ethical dilemmas on social media. The same tools were applied in the teaching sessions with the executive students who contributed to this study with their memos on digital dilemmas. Practitioners can apply these tools to their everyday challenges in coping with situations in which they must prioritize between conflicting moral and other considerations. Teachers and facilitators who design ethical training for decision-makers in organizations can use them as a starting point for systematic reflection on dilemmas. The theoretical contribution is to build on existing ethical theory and make it applicable to the particular professional need to deal adequately with social media dilemmas.

The first chapter introduced a distinction between moral intuition and ethical analysis as the fast and slow modes of decision-making when facing a dilemma. The distinction is parallel to the one Kahneman (2013) drew between fast System 1 and slow System 2 decision-making. The professionals who are responsible for handling social media accounts in their organizations can decide on a course of action based on moral intuition and gut feeling about what is right or wrong in the circumstances or engage in ethical reasoning. To proceed with the latter, they need a set of principles and concepts to guide the process. The current chapter sets out to provide a framework for slow thinking about dilemmas on social media. It builds on a method developed by Kvalnes and Øverenget (2012) and elaborated by Kvalnes (2019). A central component is the Navigation Wheel, a tool that brings attention to the dimensions of law, identity, morality, reputation, economy and ethics as relevant to decision-making.

The first section of this chapter presents a situation in which a person responsible for an organization's Facebook account encounters a dilemma. The example belongs to the same data set from which the categorization in the previous chapter emerged. The chapter will proceed with two sections presenting ethical concepts and principles in an analysis of that dilemma to illustrate how they are applicable to such cases. The second and third sections present two ethical principles that decision-makers can turn to in their analysis of available options, while the fourth section demonstrates how the Navigation Wheel can guide reasoning and decision-making when facing a dilemma in the context of organizational 
social media use. The final section proposes a method for ethical debriefing, a process in which the decision-makers step back from the situation they have been through, take stock of the events and articulate the experience. The Navigation Wheel can serve as a cognitive tool for this kind of retrospective reflection, in which the aim is to learn from the experience of having faced an ethically challenging situation.

\section{A Speech Dilemma}

The memos from the executive students who provided material for this study vary in detail and richness. Some gave very brief descriptions of their dilemmas, while others gave more detailed accounts. This chapter will focus on one of the dilemmas described most vividly to exemplify a method for ethical analysis. Here is the full description of a situation briefly outlined in the opening of Chap. 1:

One of our big construction projects is to build a long road tunnel in the mountains. It has its own Facebook page. One of my colleagues, a communications advisor, runs this page. She replies to questions and posts pictures and updates on the developments in the project. Many users follow the process and are regular visitors to the page. They like and comment on the posts. The activity generates positive energy toward the project. Sharing information on Facebook about progress and milestones creates pride among the employees. Interested locals can follow and comment on the development.

From this initial description, it is clear that this is an example of a social medium used in a positive manner. News from the construction project reaches many stakeholders and parties who take an interest in it; Facebook opens up flexible and dynamic interaction. The posts are fresh and current. Those who follow the progress of the project, both from within and outside it, can stay tuned by following and responding to the posts. Here we seem to have social media at its energizing best. 
The collaboration between the communications advisor who runs the Facebook account and the main contributor to the project-the construction manager-also appears to be in good flow:

My colleague receives photos from the project, particularly from the construction manager, who is a very good photographer. A routine has emerged where his photos are published immediately, without editing or further processing.

Based on the discussion in the previous chapter, this is where doubt can set in regarding the established collaborative routines between the communications advisor and the construction manager. The exchanges between them are very fast, with seamless steps from taking a photo and sending it to the Facebook administrator to getting it published to a wide audience. The high tempo can be exhilarating, but it also creates risk of small- and large-scale mistakes.

As the situation proceeds, it does indeed lead to publication of content that should never have been posted:

One Thursday afternoon, my colleague receives some photos from this construction manager, which she quickly posts on Facebook before going home from work.

On Friday evening, she gets a desperate phone call from the construction manager, who explains that one of the photos he has taken and that has been posted on Facebook depicts an HSE violation. The photo is from the tunnel opening, and one of the workers is not wearing a helmet.

Working without a helmet in a construction site is a major HSE violation, and now it has been documented in a Facebook post run by the organization itself. The student proceeds to explain the seriousness of the matter:

In our organization, we have recently had a range of serious accidents because of HSE violations. In the last two years, four workers have died due to sloppy HSE work on our projects. We have gone public saying that things have changed, and that we are now prioritizing safety on all our 
construction projects. It is our responsibility to monitor the subcontractors, and to make sure they abide by the HSE regulations.

The construction manager has now visited the Facebook page and seen his own photo with new eyes. The worker is clearly not wearing a helmet. More than a thousand users have seen it and some of them have posted angry messages about it. They are questioning the HSE aspect and whether we have learned anything from previous accidents and injuries.

In this unfortunate situation, a photo documenting an HSE violation has been posted and already commented upon. From the organization's point of view, it is a serious matter that (1) an HSE violation has occurred and (2) a photo of it has gone public and been spotted by concerned and critical users.

What should the communications advisor do next? The message from the person who took the photo and initially made it available for publication is clear:

Now the construction manager calls my colleague and asks her to immediately delete the post with the photo in it to avoid further exposure of the HSE mistake. My colleague hesitates but decides to do what the construction manager asks of her.

Facebook content is removed without much reflection on alternatives and consequences. Decision-making in this situation appears to have been completely System 1 driven. The intuition of the construction manager and the Facebook administrator is to remove the content as quickly as possible before more people become aware of it and more damage is done. That intuition may not be an example of moral intuition, or a sense of what one should do under such circumstances from a moral point of view, but rather a gut feeling about how to get out of an uncomfortable situation quickly.

The decision to delete the post containing the compromising photo immediately may or may not be the most adequate response. Would the decision have been the same if the two collaborators had spent $15 \mathrm{~min}$ utes or more going through the available options and reasoning calmly about their merits? That is hard to tell, but reflections on what might 
have been done differently can at least serve to prepare the decisionmakers for similar episodes later.

In the aftermath of the dramatic end to the previous week, colleagues sat down to reflect on how well the situation was handled:

On Monday morning, the colleague comes to work and explains what she did on Friday evening. We discuss whether she did the right thing. Should she have replied to the criticism before deleting the photo? Should we now post a text about the deletion, explain the circumstances and admit the HSE mistake? What should we do if a journalist contacts us with critical questions about the HSE violation and our decision to delete without commenting?

The student memo goes on to describe that they collectively decided to do nothing more regarding the deleted post. They anxiously waited for responses from the people who had initially posted critical comments, but nothing came. Apparently, the posting mistake and the subsequent deletion of the post without addressing the users' concerns did not lead to further trouble. However, the episode had been noted by some concerned users. It is possible that some of them took a screenshot of the content and stored it for later use. Even if they have not taken action yet, they may do so later in future exchanges about HSE issues in the organization.

It is unclear from the memo whether the group who debriefed about the incident on Monday agreed that the communications advisor had dealt with it in an exemplary manner and whether she or other employees should do the same again under similar circumstances. One thing they seem to have agreed upon is to ensure better quality control ahead of publishing photos.

The following sections will suggest how ethical analysis can shed light on the situation described here to illustrate more generally how decisionmakers can clarify the issues at hand before making a decision. The focus will be on the one moment in the story when the communications advisor faces a dilemma. She could either (1) respond to the users' criticism before deleting the photo or (2) delete the photo without responding to the criticism. Her quick and intuitive decision in the heat of the moment 
was to go for (2). Ethical analysis will either confirm that she actually did the right thing or disconfirm and suggest that (1) would have been a more responsible way to proceed. A third outcome of analysis may be that there are one or more other options that she did not consider that would have been ethically better. In general, ethical analysis can either strengthen or weaken the assumption that a choice based on initial impulse is in fact the one that ethical analysis singles out as the preferred one.

In light of the categorization in the previous chapter, the communications advisor faced a speech dilemma, as it involved a decision regarding what one should or should not express on a social medium. Prior to the situation, she seems to have encountered tempo dilemmas, in which a pattern of quick, impulsive and energizing behavior set the stage for mistakes. A slower tempo would have reduced the risk of mistakes but also reduced the excitement and thrill of using Facebook at work.

\section{Principle of Equality}

Consistency is a central requirement in ethical analysis and moral reasoning. It is at the core of duty ethics and Kant's categorical imperative (Kant, 1998 (1785)) but also more generally accepted across ethical theories and moral outlooks. One expression of a consistency requirement is the Golden Rule, a principle found in many religions and cultures (Wattles, 1996). It states that one should treat others in the way that one wants to be treated. The rule encourages decision-makers to imagine a turning of the tables. What if you were in that other person's shoes and they were in yours? Would you accept that the person acted toward you in the way that you are now planning to act toward that person?

Kant's consistency requirement is that the agent should act in such a way that the rule for that action could be universalized (Kant, 1983, 1998 (1785)). The agent should consider whether the actions under consideration could serve as a norm for how any other person facing the same kind of situation should act. Kant considered his categorical imperative to be an advancement of the Golden Rule because of its universal and formal nature. A limitation to the Golden Rule is that it primarily 
works for situations in which it is imaginable to swap places with the people who are affected by one's actions to consider what it would be like to be one of them. In many circumstances, that thought experiment is hard to conduct and limits the scope for reflection. A more universal and demanding consistency requirement emerges when we consider whether actions can serve as exemplary for all agents facing similar circumstances.

In a practical and organizational context, we can express the consistency requirement in a principle of equality (Kvalnes, 2019):

Equal cases should be treated equally. A difference in treatment requires that there is a morally relevant difference between the two cases.

With this principle in hand, we can explore the precise nature of the difference between superficially similar behaviors, such as giving and receiving gifts on the one hand and giving and receiving bribes on the other. From an ethical perspective, gifts are acceptable and bribes are not. The principle of equality requires that we establish a demarcation line between the two phenomena. What do we need to know to decide whether an exchange that takes place in front of our eyes is an innocent and pure gift-giving ceremony or a dubious attempt to influence a decision-maker with a bribe? A more detailed description of the context for the exchange and the involved parties reveals whether it is the one or the other. The participants' roles and motivation are relevant, and so is the value of the item changing hands.

The principle of equality also connects to fairness at work. Employees expect fair treatment and proper justification when a colleague receives special treatment in a positive or negative manner. A leader who hands out benefits or punishments to certain employees and not to others can expect to be pressured to provide justification in terms of the morally relevant differences between those who receive and those who don't.

The communications advisor who considers how to deal with a Facebook post with a photo of an HSE violation can also think in terms of consistency. From an ethical perspective, she should attempt to find an exemplary solution that can serve as a norm for how to cope with such situations. More specifically, she can explore her options through the lens 
of the principle of equality. That reflection can start from an assumption that a Facebook administrator, as a rule, should reply to comments from users and not delete posts to avoid confrontation or unpleasantness. Then again, there can be exceptions to that rule. The principle requires her to identify morally relevant differences between normal situations in which she would respond to comments and not delete posts and the current one.

The principle of equality cuts across the two main traditions of normative ethics. Both duty ethics and utilitarian ethics can accept the principle but differ on what counts as a morally relevant difference. Thus, they would provide conflicting guidance to the communications advisor in her attempt to identify morally relevant aspects of the situation. In outline, the difference between the two traditions is that duty ethics prioritizes behavior and conduct (the right) over outcomes (the good), while utilitarian ethics does the opposite by prioritizing outcomes (the good) over behavior and conduct (the right) (Kvalnes, 2019). From a utilitarian perspective, the decision-maker should choose the option that will best serve the common good and give the highest sum of utility when all stakeholders are taken into account. Duty ethics can acknowledge some moral value to beneficial outcomes without accepting that they are reached through discrediting basic moral values like respect, dignity and honesty.

A utilitarian interpretation of the principle of equality considers what constitutes a morally relevant difference in terms of whether the options strengthen or weaken the pursuit of the common good. On this account, a decision-maker should consistently try to maximize utility for all concerned.

A duty ethics interpretation of the same principle would give weight to how the available options provide moral protection to the individuals involved and exemplify respect, dignity and honesty. Consistency from this ethical perspective is to always be respectful, transparent and honest in interactions with other stakeholders.

Of the two ethical perspectives, utilitarianism is the one most likely to find some positives in the choice of deleting the compromising photo. It would prompt the decision-maker to ask what good and bad can come out of disclosure and publicity of the HSE violation. If things can be dealt with more effectively with the photo out of the way, then utilitarian 
ethics would support that option. If, on the other hand, detection of the deletion of the photo is likely to cause scandal and misadventure for the involved parties, a utilitarian would change position accordingly.

Duty ethics, on the other hand, would be minimally concerned about outcomes and more interested in the extent to which the two options are examples of honesty and respectful behavior. It would thus be critical of the decision to conceal the mistakes that have occurred, both on the construction site and in the publication of the photo. Calculations of benefits are not part of the duty ethics repertory.

\section{Principle of Publicity}

A second ethical principle to guide decision-making highlights the value of being open and transparent about one's decisions and actions. Even here, Kant's moral philosophy has played a significant role in shaping conceptions about ethical justification. It draws a link between publicity and universality, claiming that what is public is, in principle, universally available for people to think about and more or less widely known. Ethical decision-making, by Kant's account, should be transparent and free of deception and misinformation. This concern can be translated into an action-guiding principle of publicity:

Decision-makers should be willing to defend their decisions publicly and openly share their justifications with relevant stakeholders.

This line of thinking is behind various "front-page-of-a-newspaper" tests (Kvalnes, 2019). The advice to decision-makers is to consider whether they would be comfortable seeing their decision on the front page of The New York Times or another newspaper more relevant in their own context.

Going back to the Facebook case, the actual decision to delete a post with a compromising photo from the construction site is unlikely to pass the principle of publicity. "Deleted Facebook post with compromising photo" and "Ignored critical comments on HSE violation" are headlines that could easily have emerged in the local context where the story took place. One important clarification regarding the principle of publicity is 
that it should not be confused with a reputational principle. The question it poses is whether one would be willing to defend a decision publicly, not whether it is likely that one would actually have to do so. The latter reputational question would take into account the likelihood that anybody would detect or come to know about the decision. It is a characteristic feature of the ethical principle of publicity that it does not take into account the risk of detection. The likelihood that anybody would find out and leak to a news outlet may be zero, but the ethical requirement of publicity and transparency remains.

The principle of publicity makes little sense from a utilitarian perspective. Thinking about whether one would be willing to speak openly about one's decision does not in itself seem to add or distract from utility. If openness about one's pursuit of the common good could make more people understand and take up the utilitarian mindset, that would count as a positive thing, but otherwise there is no point to this thought experiment from a utilitarian point of view.

This utilitarian rejection of the principle does not mean that only decision-makers with duty ethics leanings can find it relevant. It is possible to be uncommitted to the conflict between the two normative traditions and still find it enlightening to consider one's options through the lens of this principle. If a person is hesitant or in doubt about whether he or she would be willing to justify a decision publicly, then it is a sign that this person considers the decision to be somewhat morally dubious.

With the principles of equality and publicity in place, we have a set of potentially action-guiding tools to apply when facing a dilemma in the use of social media. The next section introduces the Navigation Wheel, a model the decision-maker can use to keep track of a range of significant dimensions of the situation under consideration before making a decision. The model is primarily meant to guide the analytic process leading up to a decision but can also serve as a tool to consider the strengths and weaknesses of prior decisions and behavior. 


\section{The Navigation Wheel}

The energizing flow of information and photos from a construction project came to a halt when a photo of an HSE violation was mistakenly posted on Facebook and spotted by users. The person running the Facebook account can (1) respond to the users' criticism before deleting the photo or (2) delete the photo without responding to the criticism. In the actual case, the decision-maker received desperate calls from the photographer and construction manager and quickly followed requests to delete the photo and get it out of the way before more damage could happen. This was a clear case of System 1 decision-making, and the current chapter takes a closer and slower look at the case, primarily to introduce a set of principles and questions to ask oneself during a System 2 process of reflectively figuring out what to do.

The extent to which responsible ethical behavior in organizations builds on System 1 or System 2 decision-making is open to discussion. Egorov, Verdorfer and Peus (2018) criticized the assumption that effective decision-making in business is primarily driven by conscious deliberation and analysis and proposed an inclusion of moral intuition as a constitutive part of responsible ethical behavior. They suggest that ethical deliberation and moral intuition should be seen as mutually supportive of each other, and the current study is aligned with that proposal. The main assumption here is that fast and intuitive decision-making is not sufficient in isolation but needs support from systematic deliberation.

Stenmark, Riley and Kreitler (2019) provided backing for that assumption. They found that people who learned a structured cognitive tool for decision-making performed better after an interruption than control groups on a number of markers of ethical decision-making and exhibited perceptions that they were better prepared to handle ethical dilemmas.

The Navigation Wheel is a cognitive tool that has been applied in organizational contexts since the beginning of the century. It was originally designed as a decision-making tool for leaders and employees participating in ethical training sessions (Kvalnes \& Øverenget, 2012). Participants analyzed dilemmas in light of the six questions presented in the model (Fig. 3.1): 


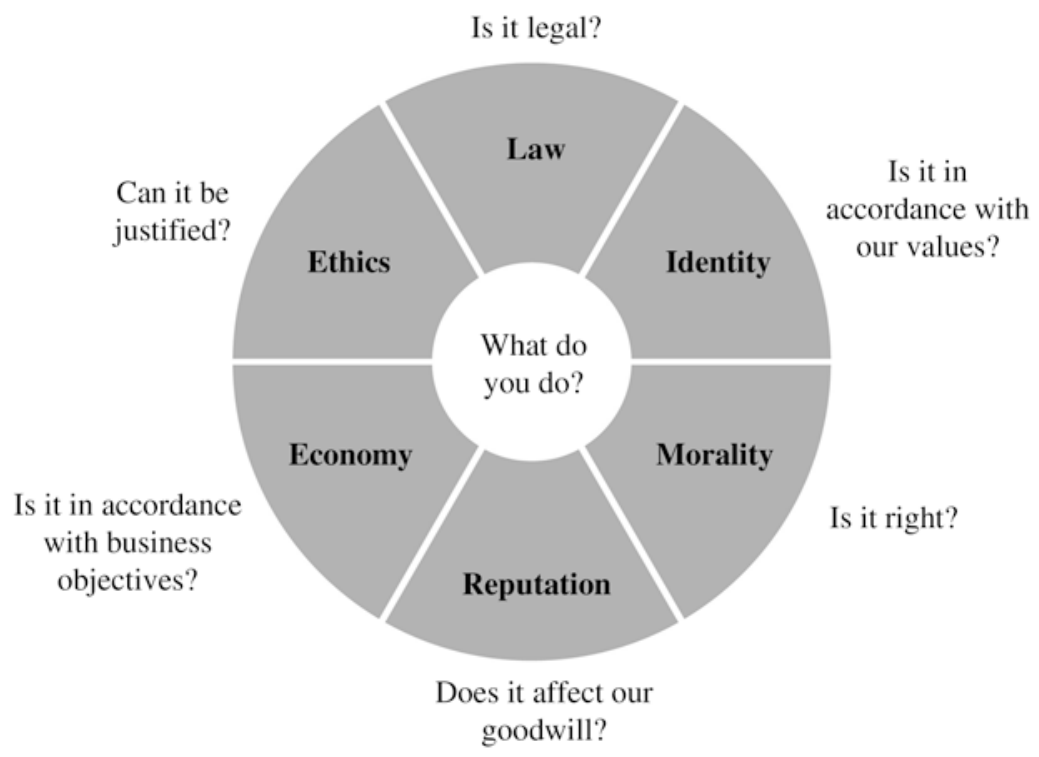

Fig. 3.1 The Navigation Wheel. (Source: Kvalnes, Ø., \& Øverenget, E. (2012). Ethical navigation in leadership training. Etikk $i$ praksis-Nordic Journal of Applied Ethics 6(1), 58-71)

The priority of questions in the model depends on context and is up to the decision-maker. The designers behind the Navigation Wheel did not envisage a particular order addressing the questions, and the relevance of each of them can vary with the situation.

The Navigation Wheel belongs to a family of models and question sets that propose a structure for analyses of dilemmas and other ethically challenging situations. One influential model is the ethical matrix (Mepham, 2000), designed to facilitate rational analysis of how decisions affect stakeholders in the domains of well-being, autonomy and justice. It has been applied in a range of contexts, including considerations of ethical challenges in agriculture (Kaiser, Millar, Thorstensen, \& Tomkins, 2007), fishing (Kaiser \& Forsberg, 2001), policy-making (Mepham, 2010) and technology (Kermisch \& Depaus, 2018).

Alternative approaches suggest different sets of questions for the decision-maker to pose: "Is it legal, is it fair, can I defend it?" (Blanchard 
\& Peale, 1988) and "Why is this bothering me?-Who else matters?-Is it my problem? - What is the ethical concern?-What do others think?Am I being true to myself?" (Rion, 1990). More complex approaches are described in van Luijk's 8-question list (2000), the 8-step list by Laczniak and Murphy (1985) and the 12-step list by Nash (1981).

A process involving the Navigation Wheel can start by identifying the most relevant options available and proceed by taking these options through the six questions in the model before using the answers and arguments that come out of that procedure as a foundation for making a decision.

Regarding LAW, the two options of (1) responding before deleting and (2) deleting without responding are both legally acceptable. There may be a legal obligation to report the HSE violation, but that is beyond the scope of the Facebook administrator's decision-making in this particular context. One noteworthy asymmetry when it comes to the legal aspect of the decision is that if an option is illegal, it constitutes a reason to refrain from choosing it, while if an option is legal, then that in itself does not constitute a reason for choosing it (Kvalnes \& Øverenget, 2012). An agent may attempt to justify a decision by saying "it is legal to do it," but that is a weak argument, since the law in a country may allow many actions that one should refrain from for other reasons than legality.

IDENTITY in this analysis has to do with organizational and professional values. The decision-maker can ask "Is it in accordance with our values?" to choose the option under consideration. First, the organization may have defined a set of core values, which are action-guiding in the sense that they rule out certain options and recommend or even prohibit certain others. If the core values in a company are honesty and trust, these define the scope of action available to employees. Secondly, the decisionmaker may belong to a particular profession where core values set the standard for what a person can and cannot do. Auditors are supposed to work from a platform of independence and objectivity; doctors and nurses are supposed to prioritize patients' interests ahead of their self-interests.

In the Facebook dilemma, we do not have information about the core values of the construction company. If they somehow highlight honesty, trust, transparency and openness, the decision-maker has strong reasons 
to reply properly to the critical messages to the post before deleting the photo. Core values may also be silent about communication with the public and so leave the decision-maker with freedom to choose between the two options.

When it comes to MORALITY, these are the moral beliefs and convictions of the decision-maker and the community that person belongs to. They manifest themselves in moral intuitions about the right course of action in a given situation. In the context of decision-making, the moral intuition may compete with other types of intuition and win or lose. During a process of deliberating about what to do, the moral aspect can come out in a reflection of whether it feels morally right or wrong to pursue a particular course of action.

The REPUTATION aspect of the decision has to do with how relevant stakeholders will respond in the event of finding out about the decision. If they are unlikely to ever receive information about it, the reputational risk is low. Here, the previously mentioned difference between the ethical principle of publicity and reputational concerns is important. The ethical question is whether one would be willing to defend the decision publicly, while the reputational question is whether one would actually have to do so. The latter question incorporates a deliberation about the risk of detection, which is not present in the former.

In the current case, the communications advisor knows that a decision to delete the photo will be known to a number of Facebook users. The reputational question she can consider is whether any of them will find it important enough to move forward with it. The HSE violation is a serious matter in light of how such violations have previously led to fatal accidents. The photo of an employee without a helmet and the subsequent deletion of the photo can be interpreted as an indication that the organization is failing to take the matter seriously. A concerned Facebook user thus has reasons to pursue the matter further. In the actual case, the decision was made very rapidly, apparently without much reflection, and may not have accounted for considerations of this kind.

ECONOMY is not a concern in the dilemma under scrutiny here, but it can be in other contexts. The options available to the decision-maker may put economic considerations up against ethical ones. The most profitable option may conflict with the organization's core values, and the 
choice may be between going bankrupt in an economic sense and with regard to identity. A dilemma can be a challenge to the integrity of a person, group or organization, in that it may pay off to flout one's own values on these three levels.

The final question in the Navigation Wheel is about ETHICS, which is where the ethical principles and theories from the previous section come in. The decision-maker can weigh his or her options by applying the principle of equality and considering which option is the most exemplary and the one to choose consistently in similar situations to the current one. That principle also encourages reflection on whether aspects of the situation warrant a break with a particular norm. "I would normally not delete content on Facebook before having replied to comments, but this situation was different" may be the introduction of a reflection pointing out morally relevant differences. When it comes to ethical theory, utilitarian ethics would accept a justification that could plausibly point to how deletion would maximize utility for the sum of stakeholders and would reject that course of action if the more plausible outcome is that stakeholders in sum would be worse off than with the alternative.

A decision-maker can (1) identify relevant options, (2) take each of them through a Navigation Wheel analysis and (3) make a decision based on that analysis. The model leaves open how to weight and prioritize the various aspects of the situation. What it does propose is a systematic way to analyze the available options and which set of questions one should take into consideration before making a decision. Justification of the decision can point back to the argumentation contained in the movement through the Navigation Wheel.

\section{$5 \quad$ Ethical Debriefing}

The primary purpose of the Navigation Wheel is to guide decisionmaking and provide a systematic framework for reflecting on available options and reaching an informed decision. It can also function as a tool for retrospective reflection about ethically challenging situations and the extent to which they are handled well. Ethical debriefing can strengthen individual and collective capabilities to cope with such situations in the 
future. Research from other areas of organizational life documents that experience in itself seldom leads to learning and enhancement of capabilities; it is a combination of experience and reflection that has the potential to do so (Di Stefano, Gino, Pisano, \& Staats, 2016; Perusso, Blankesteijn, \& Leal, 2019). The tradition of experiential learning theory elaborates on how knowledge is created through transformation of experience (Kolb, Boyatzis, \& Mainemelis, 2001; Kolb \& Yeganeh, 2011). It builds on Dewey's pragmatist philosophy and, more specifically, on the idea that deliberative restructuring of experience can add meaning to that experience and increase one's ability to direct the course of subsequent experience (Dewey, 1910). Ethical debriefing can take the form of analyzing the decision-making process to consider whether the most relevant and available options were given proper attention. Decision-makers can step away from the situation, take stock of their experience and articulate specific learning points to guide subsequent encounters with ethical dilemmas.

With the Navigation Wheel at hand, an ethical debriefing can consider the extent to which the process leading up to the decision considered the dimensions of law, identity, morality, reputation, economy and ethics for each of the alternatives. Did it neglect any of these dimensions? Which of them were particularly relevant to the decision at hand? In many situations, all the relevant alternatives are legal, so the question has never been whether one should break the law. In a well-functioning society, it is very seldom that an option to break the law comes under serious consideration in an organizational context. In those exceptional situations, the decision-maker considers civil disobedience or acting against the law for overriding moral reasons. For an example, see Kvalnes (2019, p. 52).

The reflection that constitutes an ethical debriefing can also consider the extent to which the decision under scrutiny was built on sufficient reflection or made in haste. In the main example of this chapter, it appears that the decision was built on fast System 1 thinking rather than on a slow System 2 process. One conclusion to come out of the debriefing can be that next time, one should take more time to consider the options at hand and take them through a Navigation Wheel type of analysis. Alternatively, one can conclude that future dilemmas are likely to come at a fast pace, demanding a quick and immediate response with limited 
time for ethical reflection. Under such circumstances, a possible organizational process can be to identify likely dilemmas upfront, in light of the categorization in this book or other frameworks, and then prepare for them in a slow, systematic and deliberate manner.

One factor that can stand in the way of constructive ethical debriefing is the human propensity to let actual outcomes dominate retrospective reflections and judgments. If things have turned out well, it is tempting to conclude that the ethical decision-making has been exemplary. On the other hand, if things have turned out badly, the tendency may be to think that there must have been some ethical flaws in the reasoning leading up to the decision. The concept of moral luck was mentioned in the previous chapter in connection with tempo dilemmas. The higher the tempo, the more likely that a decision will be flawed and have unwelcome consequences. Here, the concept of moral luck can serve to warn against a tendency to let actual outcomes color the moral judgment of decisions and actions, even in situations in which elements beyond the agent's control have been decisive (Nagel, 1979; Williams, 1981). Theoretically, we may think that a person should only be morally judged by what is within his or her control, but that conviction often disappears in real-life contexts, where the actual outcome takes center stage.

Moral luck constitutes a trap for those who aim to learn from their previous behavior in an ethically challenging situation. On the one hand, they may mistakenly reason that since the outcome was good, they handled the situation well. In reality, they may have simply have had good moral luck, in that a fortunate set of circumstances led to an outcome in which no one was harmed. On the other hand, bad moral luck can lead decision-makers to mistakenly reason that their initial decision was irresponsible and unethical, when in fact they have been victims of an unfortunate set of circumstances. A decision based on a reasonable risk can sometimes lead to a negative outcome, while a decision based on an unreasonable risk can lead to a positive (or at least not negative) outcome. Learning processes should focus on the situation as it was ahead of the decision and what the agents knew or were in a position to know at that time rather than on haphazard outcomes.

Empirical studies demonstrate that unlucky decision-makers are indeed judged more harshly with regard to the moral quality of their 
actions than lucky ones (Martin \& Cushman, 2016). A drunk driver who hits and injures a pedestrian is judged more harshly than a drunk driver who happens to not hurt anybody. A rescue attempt is held in higher moral regard if it is successful than if it is not, even if the difference between the two attempts are solely due to uncontrollable circumstances. The pattern is likely to hold even in social media contexts. An executive may have posted a harsh message on Twitter that would have received moral criticism if a critical world event had not occurred at the same time and took her followers' full attention. However, research also indicates that the moral difference between lucky and unlucky decision-makers and agents tends to disappear with reflection (Kneer \& Machery, 2019). Through reflection, we have the capacity to overcome what Royzman and Kumar (2004) have called epistemically corrupt evaluations. This means that a reflective and honest ethical debriefing can lead decision-makers away from the moral luck trap to a realistic understanding of what has taken place and the extent to which the situation has been handled in an exemplary way.

This chapter has presented a model for analyzing options when facing a dilemma at work involving aspects of law, identity, morality, reputation, economy and ethics. The Navigation Wheel can provide support for a slow and reflective approach to such situations, in contrast to the fast and intuitive one that often manifests itself in organizational contexts. The approach has here been exemplified through an analysis of a social media dilemma in which the decision-maker was a Facebook administrator for a company and had to find a way out of a challenging situation. We have also seen that the Navigation Wheel can have a purpose in retrospective processes and serve to structure ethical debriefing, in which the aim is to articulate the experience and reflect on it in order to learn and improve one's handling of ethical dilemmas.

Many of the executive students who contributed to the categorization of dilemmas in this study expressed concerns regarding the resources available to them when facing stressful and demanding dilemmas. Limited leadership support and a lack of guiding norms and principles put them in precarious situations where impulse and intuition often dominate over more thoughtful responses. Ethical training and familiarity with the Navigation Wheel and similar tools have the potential to 
make them better prepared for coping with ethical dilemmas on social media.

The topic of the next and final chapter is leadership and social media. The starting point is the frustration expressed by many informants regarding a lack of sufficient support from their leaders when facing ethical dilemmas. It proceeds by discussing that frustration in light of the concepts of ethical leadership and balanced leadership before ending with a proposal to research and study ethics on social media through the lens of a distinction between do-good ethics and avoid-harm ethics.

\section{References}

Blanchard, K., \& Peale, N. V. (1988). The power of ethical management. New York: William Morrow and Company. In: Inc.

Dewey, J. (1910). How we think. Boston, MA: D. C. Heath.

Di Stefano, G., Gino, F., Pisano, G. P., \& Staats, B. R. (2016). Making experience count: The role of reflection in individual learning. Harvard Business School NOM Unit Working Paper (14-093), 14-093.

Egorov, M., Verdorfer, A. P., \& Peus, C. (2018). Taming the emotional dog: Moral intuition and ethically-oriented leader development. Journal of Business Ethics, 160(3), 1-18.

Kahneman, D. (2013). Thinking, fast and slow. New York: Farrar, Straus and Giroux.

Kaiser, M., \& Forsberg, E.-M. (2001). Assessing fisheries-using an ethical matrix in a participatory process. Journal of Agricultural and Environmental Ethics, 14(2), 191-200.

Kaiser, M., Millar, K., Thorstensen, E., \& Tomkins, S. (2007). Developing the ethical matrix as a decision support framework: GM fish as a case study. Journal of Agricultural and Environmental Ethics, 20(1), 65-80.

Kant, I. (1983). Kant's ethical philosophy. Indianapolis: Hacking Publishing Company.

Kant, I. (1998 (1785)). Groundwork of the Metaphysics of Morals (M. Gregor Ed.). New York: Cambridge University Press.

Kermisch, C., \& Depaus, C. (2018). The strength of ethical matrixes as a tool for normative analysis related to technological choices: The case of geological disposal for radioactive waste. Science and Engineering Ethics, 24(1), 29-48. 
Kneer, M., \& Machery, E. (2019). No luck for moral luck. Cognition, 182, 331-348.

Kolb, D. A., Boyatzis, R. E., \& Mainemelis, C. (2001). Experiential learning theory: Previous research and new directions. Perspectives on thinking, learning, and cognitive styles, 1(8), 227-247.

Kolb, D. A., \& Yeganeh, B. (2011). Deliberate experiential learning: Mastering the art of learning from experience. In K. Elsbach, D. C. Kayes, \& A. Kayes (Eds.), Contemporary organizational behavior in action. London: Pearson.

Kvalnes, Ø. (2019). Moral reasoning at work: Rethinking ethics in organizations (2nd ed.). London: Palgrave Macmillan.

Kvalnes, Ø., \& Øverenget, E. (2012). Ethical navigation in leadership training. Etikk i praksis-Nordic Journal of Applied Ethics, 6(1), 58-71.

Laczniak, G. R., \& Murphy, P. E. (1985). Marketing ethics: Guidelines for managers. Lexington, MA: Lexington Books.

Martin, J. W., \& Cushman, F. (2016). The adaptive logic of moral luck. The Blackwell Companion to Experimental Philosophy, 190-202.

Mepham, B. (2000). A framework for the ethical analysis of novel foods: The ethical matrix. Journal of Agricultural and Environmental Ethics, 12(2), 165-176.

Mepham, B. (2010). The ethical matrix as a tool in policy interventions: The obesity crisis. In Food ethics (pp. 17-29). New York: Springer.

Nagel, T. (1979). Moral luck. In Mortal questions. Cambridge: Cambridge University Press.

Nash, L. L. (1981). Ethics without the sermon. Harvard Business Review, 59(6), 79-90.

Perusso, A., Blankesteijn, M., \& Leal, R. (2019). The contribution of reflective learning to experiential learning in business education. Assessment \& Evaluation in Higher Education, 1-15.

Rion, M. (1990). The responsible manager. San Francisco: Harper \& Row.

Royzman, E., \& Kumar, R. (2004). Is consequential luck morally inconsequential? Empirical psychology and the reassessment of moral luck. Ratio, 17(3), 329-344.

Stenmark, C., Riley, K., \& Kreitler, C. (2019). Ethical decision-making interrupted: Can cognitive tools improve decision-making following an interruption? Ethics \& Behavior, 1-24.

Van Luijk, H. J. L. (2000). In search of instruments. Business and ethics halfway. In Business challenging business ethics: New instruments for coping with diversity in international business (pp. 3-8). New York: Springer. 
Wattles, J. (1996). The Golden rule. New York: Oxford University Press.

Williams, B. (1981). Moral luck: Philosophical papers 1973-1980. Cambridge: Cambridge University Press.

Open Access This chapter is licensed under the terms of the Creative Commons Attribution 4.0 International License (http://creativecommons.org/licenses/ by/4.0/), which permits use, sharing, adaptation, distribution and reproduction in any medium or format, as long as you give appropriate credit to the original author(s) and the source, provide a link to the Creative Commons licence and indicate if changes were made.

The images or other third party material in this chapter are included in the chapter's Creative Commons licence, unless indicated otherwise in a credit line to the material. If material is not included in the chapter's Creative Commons licence and your intended use is not permitted by statutory regulation or exceeds the permitted use, you will need to obtain permission directly from the copyright holder.

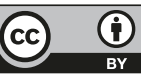

